\title{
Trial Sets Supplemental Qualifiers Dataset
}

National Cancer Institute

\section{Source}

National Cancer Institute. Trial Sets Supplemental Qualifiers Dataset. NCI Thesaurus.

Code C147266.

A dataset containing supplemental information, specifically non-standard variables, to parent records in the trial sets domain. 